\title{
Oral and systemic manifestations in HIV-1 patients
}

\author{
Tatiany Oliveira de Alencar Menezes ${ }^{[1]}$, Marília Corrêa Rodrigues ${ }^{[1]}$, \\ Brenna Magdalena Lima Nogueira[1], Sílvio Augusto Fernandes de Menezes ${ }^{[2]}$, \\ Sílvia Helena Marques da Silva ${ }^{[3]}$ and Antonio Carlos Rosário Vallinoto ${ }^{[4]}$
}

[1]. Faculdade de Odontologia, Instituto de Ciências da Saúde, Universidade Federal do Pará, Belém, PA. [2]. Clínica Odontológica, Centro Universitário do Estado do Pará, Belém, PA. [3]. Laboratório de Micologia, Departamento de Bacteriologia e Micologia, Instituto Evandro Chagas, Anannideua, PA, [4]. Laboratório de Virologia, Instituto de Ciências Básicas, Universidade Federal do Pará, Belém, PA.

\begin{abstract}
Introduction: This study aimed to estimate the prevalence of the most frequent oral and systemic manifestations in human immunodeficiency virus-1 (HIV-1)-positive patients. Methods: The study was conducted on 300 HIV-1 patients attending the Reference Unit Specialized in Special Infectious Parasitic Diseases in Belém, Pará, Brazil. Results: The most prevalent oral conditions were caries $(32.6 \%)$, candidiasis $(32 \%)$, and periodontal disease $(17 \%)$. Among the systemic manifestations, hepatitis $(29.2 \%)$, gastritis (16\%), arterial hypertension (14.7\%), and tuberculosis (12\%) were the most commonly observed. Conclusions: We here reported on the most prevalent oral and systemic conditions in HIV-1-positive patients. The healthcare professional's knowledge of the various manifestations among these patients is fundamental to ensure prompt and accurate diagnosis and treatment, and for improving the quality of life of these patients.
\end{abstract}

Keywords: HIV. AIDS. Dentistry.

Acquired immunodeficiency syndrome (AIDS) is characterized by a severe depletion of the immune system as a result of human immunodeficiency virus (HIV) infection, which causes a reduced number of CD4 $\mathrm{T}$ lymphocytes. In humans, these cells are responsible for the immunologic defense, and their reduced count results in the onset of various infirmities, including opportunistic infections and malignant tumors; accordingly, these are considered indicators of $\operatorname{AIDS}^{(1)}$. In 2012, approximately 34 million people were reportedly to have $\operatorname{AIDS}^{(2)}$.

According to Ioachim ${ }^{(1)}$, HIV infection can be divided into four phases: acute infection, the asymptomatic or latent phase, the initial or early symptomatic stage, and AIDS. The first phase is characterized by an acute infection, which may appear a few weeks after the initial infection; the disease is seldom diagnosed in this phase, as the symptoms resemble those of other, more common viral infections. The second, asymptomatic, phase has a variable duration, ranging from a few months to several years. Symptomatic disease occurs as the patient begins to present with changes in immunity, as indicated by the appearance of opportunistic infections and a reduced TCD4+ cell count.

According to the 2013 Epidemiological Bulletin of the Brazilian Ministry of Health, there were 39,185 cases of

\footnotetext{
Address to: Dr. Antonio Carlos Rosário Vallinoto. Laboratório de Virologia/ ICB/UFPA. Rua Augusto Corrêa nº 01, Guamá, 66075-110 Belém, PA, Brasil. Phone: 5591 3201-7587

e-mail: vallinoto@ufpa.br

Received 4 August 2014

Accepted 17 October 2014
}

AIDS reported in 2012; this figure has been stable in the past 5 years. The national rate of detection was 20.2 cases for every 100,000 inhabitants, with the highest rate observed in the South Region (30.9/100,000 inhabitants), followed by the North $(21.0 / 100,000)$, Southeast $(20.1 / 100,000)$, CenterWest (19.5/100,000), and Northeast Regions (14.8/100,000 inhabitants). Of the total 709,477 cases of AIDS identified in Brazil between 1980 and 2013, 64,268 (9.1\%) patients have died of the disease; of these, 43,184 (67.2\%) cases were male and 21,079 (32.8\%) were female ${ }^{(3)}$.

Oral manifestations occur as a result of the compromised immune system. A total of $50 \%$ of HIV-positive patients reportedly display oral lesions, and therefore, the oral cavity becomes an important source of information to aid in the diagnosis, as these lesions are among the first clinical signs of HIV infection and are able to predict its progression to $\operatorname{AIDS}^{(4)}$.

Studies have shown that the oral manifestations most commonly result from fungal, bacterial, and viral infections ${ }^{(5)}$. Among the fungal infections, oral candidiasis caused by Candida albicans is one of the most common opportunistic diseases associated with HIV infection, of which the erythematous and pseudomembranous forms have a greater incidence, followed by angular cheilitis. It is believed that these manifestations are related to the immunosuppression caused by the reduced CD4+ T lymphocyte count, as well as local factors such as xerostomia ${ }^{(6)}$.

HIV-associated gingivitis stands out among the bacterial infections. This disease is characterized by severe erythema in the marginal and attached gingiva and alveolar mucosa. It may display an erythematous halo and may be accompanied 
by occasional bleeding and discomfort ${ }^{(7)}$. Moreover, necrosisassociated periodontitis may lead to tooth mobility due to the rapid loss of bone and soft tissue, consequently resulting in bleeding, an unpleasant smell, and intense pain over the entire maxilla and jaw area ${ }^{(8)}$.

In addition to the oral manifestations in HIV patients, there are several systemic manifestations associated with the virus, and these can severely worsen the individual's prognosis. Diseases commonly found in these patients include tuberculosis (TB), hypertension, and hepatitis $\mathrm{B}$ and $\mathrm{C}^{(9)}$. Another noteworthy manifestation is atypical ulcers of unknown etiology, which can present with different levels of severity ${ }^{(1)}$.

Thus, considering the high incidence of several opportunistic diseases in HIV-1 patients, the present study aimed to estimate the prevalence of the most frequent oral and systemic manifestations in the Reference Unit Specialized in Special Infectious Parasitic Diseases (Unidade de Referência Especializada em Doenças Infecciosas Parasitárias Especiais - UREDIPE) in Belém, Pará, Brazil.

This study was submitted to and approved by the Research Ethics Committee of the Institute of Health Sciences of the Federal University of Pará (ICS- UFPA; process no. 120/09), and was conducted in accordance with the Declaration of Helsinki, the Nuremberg Code, and the Normas de Pesquisa Envolvendo Seres Humanos [Research Guidelines for Studies Involving Human Beings] (Res. CNS 196/96 and complements thereof) of the Brazilian National Health Council.

In the present investigation, we evaluated the clinical and epidemiological data of 300 cases. Patients of both sexes who were $>18$ years of age and had a record at the UREDIPE in Belém, Pará, Brazil were randomly included in the study. The information on oral manifestations was obtained while the patients received care in the dental clinic. All data were recorded on a form specifically designed for this study.

The data were input into Microsoft Office Excel 2010 (Microsoft corp., Redmond, WA, USA) and analyzed descriptively regarding the relative frequencies observed.

Of the $300 \mathrm{HIV}$-positive patients included in the study, $52.7 \%$ were male, and the mean age was $39 \pm 9.06$ years (range, 18-66 years).

Regarding the presence of oral manifestations, 51 (17\%), $96(32 \%)$, and $98(32.6 \%)$ cases of periodontal disease, candidiasis, and caries lesions, respectively, were observed. The distribution of cases with systemic manifestations was as follows: TB (12\%), arterial hypertension (14.7\%), hepatitis (29.2\%), and gastrointestinal disorders (e.g. gastritis) (16\%) (Table 1).

AIDS is considered a global pandemic, and is caused by the continuous destruction of CD4+ T lymphocytes. HIV-1positive individuals become susceptible to several opportunistic infections with a wide array of symptoms and clinical signs, and the oral cavity is the site for many of these manifestations ${ }^{(2)(5)}$.

The occurrence of oral lesions in AIDS patients has been the focus of several studies due to their significant diagnostic value, as these oral manifestations generally account for the first clear symptoms and signs of the disease ${ }^{(5)(10)}$. Studies have reported
TABLE 1 - Oral and systemic clinical manifestations in human immunodeficiency virus-1-positive patients $(n=300)$.

\begin{tabular}{lcc}
\hline Variables & Number & Percentage \\
\hline Oral conditions & & \\
Dental caries disease & & \\
yes & 98 & 32.6 \\
no & 202 & 67.4 \\
Candidiasis & & \\
yes & 96 & 32.0 \\
no & 204 & 68.0 \\
Periodontal disease & & \\
yes & 51 & 83.0 \\
no & 249 & \\
\hline
\end{tabular}

Systemic conditions

Hepatitis

yes

87

29.2

no

213

Gastritis

yes

no

Arterial hypertension

yes

no

Tuberculosis

yes

no

Diabetes

yes

Kidney disease

yes

no

Convulsion

yes

Cardiac alterations

$$
\text { yes }
$$

Ulcer 
that oral lesions correspond to infections caused mainly by fungi, bacteria, and viruses, in addition to tumors and other entities of unknown cause, and numerous studies have confirmed the relationship between HIV-mediated immunosuppression and the incidence and severity of common periodontal diseases such as adult chronic periodontitis ${ }^{(1)}$.

In the present study, out of the 300 patients analyzed, we observed a predominance of male compared to female patients $(52.7 \%$ vs. $47.3 \%)$, and these proportions are similar to those reported by Gasparin et al. ${ }^{(11)}$.

Among the lesions of fungal origin associated with HIV infection, candidiasis is of great clinical importance, as it can trigger systemic infections conditions in immunosuppressed patients. In the present study, oral candidiasis was one of the most frequent manifestations, observed in $32 \%$ of the cases. This result is in agreement with that of Pomatico et al. ${ }^{(12)}$, who reported a high rate of HIV-1 individuals with fungal infections due to deep alterations in their immune systems; in such patients, candidiasis is the first lesion to manifest itself, with a reported frequency between $3 \%$ and $30 \%$.

Candidiasis is associated with low TCD4+ levels, and there is a consensus among several authors that candidiasis hence represents a marker of rapid progression of the disease. Accordingly, it is an important warning signal of HIV infection, and this makes the early detection of candidiasis particularly important ${ }^{(13)}$.

Another clinical finding was periodontal disease in $17 \%$ of the subjects. This oral condition is characterized by a set of chronic inflammatory diseases that affect the tissues supporting the teeth, and is relatively common among the general adult population $^{(8)}$.

According to Motta et al. ${ }^{(4)}$ and Glick et al. ${ }^{(9)}$, periodontal disease is promoted by changes in the mouth's normal microbiota, with increased proliferation of subgingival gramnegative anaerobic bacteria, and is caused by a reduction in the saliva's capacity to control the microbiota and bacterial plaque, consequently resulting in the development of gum and periodontal lesions. Kinane et al. ${ }^{(14)}$ reported that individuals with TCD4+ levels below 200 cells $/ \mathrm{mm}^{3}$ present with a more severe loss of insertion in chronic periodontitis, which suggests that preexisting periodontitis may be exacerbated in HIVpositive individuals. These findings are also in agreement with those of Glick et al. ${ }^{(9)}$, who suggested that the immunodeficiency caused by HIV infection directly affects the pathogenesis of periodontal disease, given that individuals affected by the virus commonly present with oral lesions associated with immunosuppression.

Among the 300 patients included in this study, caries lesions occurred in 98 (32.6\%) cases. Dental caries is the most prevalent infectious disease in humans and the one of greatest incidence. The results of the present study confirmed the high incidence of oral disorders in HIV-1-positive patients, indicating the importance of prioritizing oral cavity examinations and oral hygiene instructions, especially for these patients ${ }^{(10)(12)(14)}$.
Tuberculosis is the second most prevalent opportunistic infection among AIDS patients in Brazil ${ }^{2}$. HIV infection significantly increases the risk of developing active $\mathrm{TB}^{(14)}$ and the co-infection of HIV and TB is associated with increased mortality rates, thus posing a serious public health challenge ${ }^{(2)}$. In this study, the prevalence of TB was observed in 36 cases, corresponding to $12 \%$ of the subjects. According to Hino et al. ${ }^{(14)}$, the TB problem in Brazil is a reflection of the stage of social development in the country, where the lack of adequate sanitation and institutional deficiencies in the health system has limited the achievement of goals for controlling TB, thereby precluding eradication of the disease.

Another factor widely reported in the literature is the correlation between HIV and viral hepatitis (hepatitis B and $\mathrm{C}$ ), owing to the fact that both these infections share the same transmission routes (parenteral, sexual, and vertical) ${ }^{(2)}$. In accordance with these results, in the present study, 87 (29.2\%) cases of hepatitis were found.

Regarding arterial hypertension, 44 (14.7\%) cases were identified. It is known that arterial hypertension in HIV-positive patients may be associated with the same risk factors as the population in general or, as indicated by some studies, may be related to the use of antiretroviral drugs ${ }^{(15)}$.

While drugs such as protease inhibitors promote the suppression of viral replication and reduce HIV multiplication, this class of drugs also increases the risk of insulin resistance and diabetes. Soon after antiretroviral drugs were first introduced, the United States Food and Drug Administration reported 83 cases of hyperglycemia among HIV-infected individuals using protease inhibitors, suggesting a possible association between this class of drugs and glycemic disorders ${ }^{(15)}$. Accordingly, in the present study, 12 (4\%) patients presented with diabetes. Furthermore, changes in the blood sugar levels may also occur before the use of antiretroviral drugs as a result of the chronic inflammation caused by the virus itself.

Lastly, in the present study, $3 \%$ of the patients displayed kidney alterations. Nonetheless, despite this relatively low incidence, this result reinforces the importance of detailed investigations of the kidney in HIV-positive patients, as kidney disease may affect the quality of life and mortality in these patients.

Most patients seek dental care only when experiencing painful symptoms in the oral cavity. This finding is alarming, as the presence of lesions in the oral cavity facilitate the diagnosis of HIV and can therefore result in more prompt treatment. Based on the results obtained herein, the prevalence of certain oral and systemic manifestations associated with HIV infection is high, with caries, candidiasis, and periodontal disease being the most common oral conditions. On the other hand, the most prevalent systemic manifestations were tuberculosis, arterial hypertension, hepatitis, and gastritis. The healthcare professional's knowledge of these manifestations among HIVpositive patients is fundamental to ensure prompt and accurate diagnosis and treatment, and consequently, for improvements in the quality of life of these patients. 


\section{ACKNOWLEDGMENTS}

We thank all individuals who participated in the research and those involved in sample collection.

\section{CONFLICT OF INTEREST}

The authors declare that there is no conflict of interest.

\section{FINANCIAL SUPPORT}

This study was partially supported by a grant from the Brazilian National Council for Scientific and Technological Development $(\mathrm{CNPq})$ and the Office of the Dean of Research and Graduate Studies (Pró-Reitoria de Pesquisa e Pós-Graduação - PROPESP/UFPA)/Research Support and Development Foundation (Fundação de Apoio e Desenvolvimento da Pesquisa - FADESP).

\section{REFERENCES}

1. Ioachim HL. Immunopathogenesis of human immunodeficiency virus infection. Cancer Res 1990; 50:S5612-S5617.

2. Joint United Nations Programme on HIV/AIDS (UNAIDS). Global report: UNAIDS report on the global AIDS epidemic. Geneva: WHO Library Cataloguing-in-Publication Data; 2012.

3. Ministério da Saúde. Boletim epidemiológico AIDS-DST. Semanas Epidemiológicas. Brasília: Ministério da Saúde; 2013.

4. Motta WKS, Nóbrega DRM, Santos MGC, Gomes DQC, Godoy GP, Pereira JV. Aspectos demográficos e manifestações clínicas bucais de pacientes soropositivos para o HIV/Aids. Rev Odontol UNESP 2014; 43:61-67.
5. Reznik DA. Oral manifestations of HIV disease. Top HIV Med 2006; 13:143-148.

6. Sharma G, Pai KM, Setty S, Ramapuram JT, Nagpal A. Oral manifestations as predictors of immune suppression in a HIV-/ AIDS-infected population in south India. Clin Oral Invest 2009; 13:141-148.

7. Cavassani VGS, Sobrinho JA, Homem MGN, Raport A. Candidíase oral como marcador de prognóstico em pacientes portadores do HIV. Rev Bras Otorrinolaringol 2002; 68:630-634.

8. Petruzzi MNMR, Salum FG, Cherubini K, Figueiredo MAS. Epidemiological characteristics and HIV-related oral lesions observed in patients from a Southern Brazilian city. Rev Odonto Ciência 2012; 27:115-120.

9. Araújo GB, Souza DC, Oliveira APS, Santos BCL, Cunha PA, Moia LJMP. Aspectos clínico-epidemiológicos de pacientes com o vírus da imunodeficiência humana e marcadores sorológicos para o vírus da hepatite B. Rev Soc Bras Clin Med 2013; 11:238-241.

10. Glick M, Holmstrup P. Infecção pelo HIV e doenças Periodontais. In: Rose M, Genco C, editors. Medicina periodontal. São Paulo: Santos; 2002. p. 183-193.

11. Miziara ID, Lima AS, Cortina RAC. Candidíase oral e leucoplasia pilosa como marcadores de progressão da infecção pelo HIV em pacientes brasileiros. Rev Bras Otorrinolaringol 2004; 70: 310-314.

12. Gasparin AB, Ferreira FV, Danesi CC, Mendoza-Sossi RA, Silveira J, Martinez AMB, et al. Fatores e prevalências associados às manifestações bucais em pacientes HIV positivos atendidos em cidades sul-brasileiras. Cad Saude Publica 2009; 25:1307-1315.

13. Kinane DF. Periodontitis modified by systemic factors. Ann Periodontol 1999; 4:54-64.

14. Hino P, Cunha TN, Villa TCS, Santos CB. Perfil dos casos novos de tuberculose notificados em Ribeirão Preto (SP) no período de 2000 a 2006. Cien Saude Colet 2011; 16 (supl I):1295-1301.

15. Baekken MOI, Sandvik L, Oektedalen O. Hypertension in an urban HIV-positive population compared with the general population: influence of combination antiretroviral therapy. J Hypertens 2008; 26:2126-2133. 